\title{
Study on the Subjectivity of Nursing Students' Perception of Diet
}

\author{
Sunyoung Jang \\ Department of Nursing, Hanseo University, 46 Hanseol Ro, Haemi-myun, Seosan-si, \\ Chungcheongnam-do, 369-709, Korea \\ sjang@hanseo.ac.kr
}

\begin{abstract}
This study aims to identify the subjectivity for the categorization of the diet with whom nursing students. The study has utilized $Q$ Methodology. 19 nursing students, with clinical training experience at hospitals, were asked to classify 44 statements on the perception. The collected data was analyzed by the Principle Component Factor Analysis of the QUANL PC Program. In this study, the types of clinical practice were categorized into 3 types: the diet type compelled by circumstances', 'the diet type for health', and 'the diet type for additional benefits' This study has provided the baseline data for education and counseling program development for nursing students who start clinical practice.
\end{abstract}

Keywords: Diet, Nursing student, Subjectivity, Q-methodology, Nurse

\section{Introduction}

\subsection{Necessity of study}

The word diet stems from the Greek diaita which the ancient Greeks used to diet for health. However, as the Industrial Revolution of the 19th century brought economic wealth, the pursuit of beauty backed up by economic wealth opened the beginning of a diet for beauty and losing weight [1]. That kind of tendency has continued into modern days and even so many people with normal weights are seriously on diets regardless of gender and age under the circumstances of society favoring beauty and sleek appearances.

In this modern society, there are social environments causing obesity, and, on the flip side, there is also the pressure of media praising slim appearances. Consequently, many people go on diets even though they have normal weights or are even below normal weights [2]. It is very prone to return to the previous weight even if any obese person loses weight once. That is why curing obesity is difficult. On the other hand, regaining weight following a diet increases the risk of cardiovascular disease and causes an additional burden on the public health system. Meanwhile, the cases of health risks coming from regaining weight following diets are found more frequently in people with normal weights than obese or overweight people [3].

Nurses take up the largest portion of the field of public health and are the core human resources who contact patients most frequently. They should provide a high level of nursing services to patients within a limited time frame under the circumstances of the rapidly changing public health sector [4]. The subjectivity of nurses' perception in the field of public

Article history:

Received (June 2, 2020), Review Result (July 9, 2020), Accepted (August 12, 2020) 
health greatly influences their nursing services. Therefore, it is important to find out the perceptions of the nurses and the nursing students.

Studies regarding nurses' perceptions of diet are not easy to find. Q-methodology is based on the perspectives of the behaving persons rather than researchers and makes it possible to structurally understand the characteristics of individual types of subjectivity [5]. Since the perception of diet is a subjective and unique experience, it is appropriate to use the Qmethodology to find out the types of nurses' perceptions of diet.

Therefore, this study is intended to find out the subjectivity structure of nurses' perception of diet and use it as the underlying material for the development of education programs for nursing students which is differentiated based on the characteristics of each type of perception of diet.

\subsection{Purpose of study}

This study found out the types of undergraduate students' subjective perceptions of diet and the characteristics of the types so that it can be used as the underlying material when preparing a strategy for the provision of education to nursing students learning about diet. To reiterate the purpose of this study, they are:

To categorize the types of nursing students' perceptions of diet.

To analyze and describe the types of nursing students' perceptions of diet.

\section{Method of study}

\subsection{Design of study}

To achieve the purpose of this study, I reviewed literature, media materials, and existing studies and surveyed to find out the types of subjective recognition of diet.

\subsection{Q Population and Q sample selection}

Q population was drawn through a review of domestic and international literature, open questionnaires, individual in-depth interviews, etc. to get comprehensive statements regarding the effects of diet on nursing students in their undergraduate years in our country. Through this process, I have drawn about $200 \mathrm{Q}$ populations in 3 areas and have drawn about $100 \mathrm{Q}$ populations by integrating collected literature. I have selected the final 49 samples which have a high level of differentiation through the review and correction of Q samples drawn from this study.

\subsection{Method of selecting p-sample}

Q-methodology is the qualitative research method that emphasizes personal tendency by focusing on personal implication or significance rather than personal differences. It is based on the small sample doctrine that says if P-sample gets large, too many people get concentrated in one factor, thereby making it hard to find out the characteristics among themselves [6]. I have fully explained the purpose of this study to the students of the nursing department in a certain university and selected 19 students from them who agreed to participate in this study. 


\subsection{Classification and data analysis method}

Q-classification is the process in which the participants who belong to the P-sample make the voluntary definition of diet by classifying the statements of the Q-sample into forced normal distribution [6]. This process was conducted for the 19 students of the nursing department in a certain university by using Q-card. Most of the students consumed 30-45 minutes to complete the Q-classification. The distribution of the Q-sample is classified from strongly agree to strongly disagree depending upon the opinions of the participants on the statements selected for the Q-sample. The statements on diet were classified on 12 points scale. Subsequent interviews were conducted regarding the statements classified at both extreme ends. Principle Component Factor Analysis (varimax) was used for Q-factor analysis. Classification of types was determined by considering results, which are calculated by entering various numbers of factors with more than Eigenvalue 1.0, and the total explanation variants. For collected materials, conversion scores of 1 12 are assigned for scoring based on the card which has forced distribution on the Q-sample distribution table. The converted scores assigned were encoded in the sequence of Q-sample numbers and were processed by the Principle Component Factor Analysis of the QUANL PC Program. Analysis of the materials was processed by using QUANL PC Program [7][8].

\subsection{Ethical considerations for the subject}

I obtained voluntary consent from the participants for our research and explained that any of them may discontinue participating at any time during the research. All the information collected from this research was processed without the identification of participants and was coded for Q-sorting to guarantee the confidentiality of personal information.

\section{Result of study}

\subsection{Structure of Q-type}

As a result of the Q-factor analysis of the nursing students' subjectivity of diet by using the QUANL PC Program, 3 kinds of types were found.

\subsection{Analysis of individual types}

Type recognizing neighboring circumstances as the major factor: 7 participants belonged to this type. The statements which were strongly agreed by the participants were: "Diet is necessary for Korean society $(\mathrm{z}=1.69)$ ", "Diet is compelled by the stress coming from the way people look at me $(\mathrm{z}=1.74)$ ", and "Unverified methods of diet is on the rise $(\mathrm{z}=1.43)$ ". No. 1 was the respondent who had the highest factor weight in this 1st type (1.5843) and the respondent strongly agreed with statements 4 and 10 . The statements which were strongly disagreed by the participants were: "Diet has nothing to do with individual characteristics ( $\mathrm{z}=-$ 1.94)", "Medicine should be used for diet ( $\mathrm{z}=-1.64)$ ", and "People with higher education tend to be interested in diet ( $\mathrm{z}=-1.56)$ [Table 1]". No. $11(0.4627)$ was the respondent who had the lowest factor weight in this 1st type and the respondent strongly disagreed with statements 32 and 2.

They responded that human beings are social creatures and social recognition influences their behaviors. Therefore, they said, the desire for diet shall vary depending upon the level of social recognition they feel. Also, they thought diet is the offspring of human society and the criteria of diet are different from society to society. In that regard, they answered that changes 
in social recognition are more important than personal efforts to prevent excessive diet and establish the practices of desirable diet. From the context of the above mentioned, I name this type as "the type recognizing neighboring circumstances as the major factor".

Table 1. Q-statements on diet and Z-scores of factor $1(\mathrm{~N}=7)$

\begin{tabular}{|c|c|c|c|}
\hline No & Description & Mean (SD) & Z-score \\
\hline 4 & Diet is necessary for Korean society. & $10.57(2.507)$ & 1.96 \\
\hline 10 & Diet is compelled by others staring at me with prejudice. & $10.71(1.113)$ & 1.74 \\
\hline 27 & Unverified method of diet is on the rise. & $9.43(1.618)$ & 1.43 \\
\hline 32 & Diet has nothing to do with personal characteristics. & $3.29(1.704)$ & -1.94 \\
\hline 2 & Medicine should be used for diet. & $3.57(2.636)$ & -1.64 \\
\hline 35 & Persons of higher education are more interested in diet. & $3.86(1.676)$ & -1.56 \\
\hline
\end{tabular}

Type pursuing health: 7 participants belonged to this $2^{\text {nd }}$ type. The statements which were strongly agreed by these participants were: "Balanced meals are helpful for diet $(z=2.43)$ ", "I do the diet to keep healthy $(\mathrm{z}=1.83)$ ", and "Aerobic exercise is good for health $(\mathrm{z}=1.45)$ " [Table 2]. No. 4 was the respondent who had the highest factor weight in this $2^{\text {nd }}$ type (1.2258) and the respondent strongly agreed with statements 19 and 7 . The statements which were strongly disagreed by the participants were: "Medicine should be used for diet $(\mathrm{z}=-2.27)$ ", "Diet has nothing to do with individual characteristics $(\mathrm{z}=-2.06)$ ", and "Diet is necessary regardless of body weight ( $\mathrm{z}=-1.59) "$. [Table 2] No. 9 (0.5061) was the respondent who had the lowest factor weight in this $2^{\text {nd }}$ type and the respondent strongly disagreed with statements 2 and 32.

They maintain that the eventual purpose of the diet is to have a healthy and happy life. They think the effect of diet can be achieved by changing basic patterns of life and it will vitalize our lives. In this regard, I named this type as the type pursuing health.

Table 2. Q-statements on diet and Z-scores of factor 2(N=7)

\begin{tabular}{|c|c|c|c|}
\hline No & Description & Mean (SD) & Z-score \\
\hline 19 & Balanced meals are helpful for diet. & $11.57(1.272)$ & 2.43 \\
\hline 7 & Diet is done for health. & $10.29(1.976)$ & 1.83 \\
\hline 33 & Aerobic exercise is good for the diet. & $9.71(2.289)$ & 1.45 \\
\hline 2 & Medicine should be taken for diet. & $2.57(1.272)$ & -2.27 \\
\hline 32 & Diet has nothing to do with personal characteristics. & $3.00(1.732)$ & -2.06 \\
\hline 11 & The diet should be done regardless of body weight. & $4.00(1.155)$ & -1.59 \\
\hline
\end{tabular}

Type pursuing additional benefits: 5 participants belonged to this $3^{\text {rd }}$ type. The statements which were strongly agreed by these participants were: "Cognitive efforts are necessary to restrain the desire to have foods $(\mathrm{z}=2.51)$ ", "females are more likely to go on diets than males $(\mathrm{z}=1.99)$ ", and "Diet is important for mental and physical health $(\mathrm{z}=1.97)$ " [Table 3]. No. 19 was the respondent who had the highest factor weight in this $3^{\text {rd }}$ type $(1.1523)$ and the respondent strongly agreed with statements 26 and 1 . The statements which were strongly 
disagreed by the participants were: "Diet must be done regardless of body weight ( $\mathrm{z}=-2.59)$ ", "Married person is likely to go on a diet $(\mathrm{z}=-1.61)$ ", and "Diet for purely reducing body weight is on the rise $(\mathrm{z}=-1.57)$ [Table 3].

The respondents are interested in the additional benefits of the diet. They focus on the changes in life following the diet. They supposed that a balanced body and psychological confidence coming from diet shall bring changes in their lives and improve the quality of their lives. In this regard, I name this type as the type pursuing additional benefits.

Table 3. Q-statements on diet and Z-scores per factor of factor $3(\mathrm{~N}=5)$

\begin{tabular}{|c|c|c|c|}
\hline No & Description & Mean (SD) & Z-score \\
\hline 26 & Cognitive efforts to restrain appetite are necessary. & $10.00(3.674)$ & 2.51 \\
\hline 1 & Females go on diets more frequently than males. & $9.00(4.123)$ & 1.99 \\
\hline 3 & Diet is important both for mental and psychological health. & $9.40(3.578)$ & 1.97 \\
\hline 11 & The diet should be done regardless of body weight. & $3.80(4.087)$ & -2.59 \\
\hline 36 & A married person is more likely to go on a diet. & $4.80(2.280)$ & -1.61 \\
\hline 14 & Cases of diets for merely reducing body weight are on the rise. & $4.40(2.966)$ & -1.57 \\
\hline
\end{tabular}

\section{Discussion}

As a result of the research, three types of nursing students' subjective perception of diet were found, which are: the $1^{\text {st }}$ type recognizing neighboring circumstances as the major factor, the $2^{\text {nd }}$ type pursuing health, and the $3^{\text {rd }}$ type pursuing additional benefits. Let us discuss the characteristics of the types in the following.

The $1^{\text {st }}$ type found in this study was the type that recognized neighboring circumstances as the major factor. They think people begin dieting because of the neighboring circumstances. They suppose preconceptions of others and the social atmosphere make them begin their diet. Since every society is unique and various, the level of obesity and the emotional pressure for diet shall be different depending upon which society a person belongs to. Therefore, they suppose that an undesirable diet can be prevented by changing prejudice and the notion of a society if a society has problematic criteria of beauty or has some sort of discrimination.

The $2^{\text {nd }}$ type found in this study was the type pursuing health. They think diet should be done to achieve a healthy life and it should be conducted through changes into desirable daily habits including exercises and balanced meals. They also think diet is not necessary for all people but shall be necessary for a certain type of people for their healthy lives.

The $2^{\text {nd }}$ type found in this study was the type pursuing health. They think diet should be done to achieve a healthy life and it should be conducted through changes into desirable daily habits including exercises and balanced meals. They also think diet is not necessary for all people but shall be necessary for a certain type of people for their healthy lives.

This study analyzed the subjectivity of nursing students' perception of diet by categorizing them into 3 types. Most of the nursing students thought not all people need to go on diets and it is selectively necessary for certain cases. They also thought diet should be done in healthy and reasonable ways without the risk of side effects. The $1^{\text {st }}$ type that recognizes neighboring circumstances as the major factor supposes that they do diet because of circumstances, the $2^{\text {nd }}$ type that pursues health goes on a diet for health, and the $3^{\text {rd }}$ type that pursues additional benefits goes on a diet because of additional benefits which follow the successful diet. This 
kind of study on the subjectivity of perception of diet can be used as the basic information for the development of diet methods and treatment of obesity. In addition, we anticipate that this can be used also as the basic information for the development of differentiated education programs to be provided to nursing students in their undergraduate years.

However, this study has limitations in the generalization of the results since the research was conducted only at one certain university and could not select respondents in consideration of factors influencing the perception of diet. Therefore, it is necessary to subsequently verify the 3 types by drawing Q-sample from various backgrounds.

\section{Conclusion}

This study analyzed the subjectivity of nursing students' perception of diet by categorizing them into 3 types. Most of the nursing students thought not all people need to go on diets and it is selectively necessary for certain cases. They also thought diet should be done in healthy and reasonable ways without the risk of side effects. The $1^{\text {st }}$ type that recognizes neighboring circumstances as the major factor supposes that they do diet because of circumstances, the $2^{\text {nd }}$ type that pursues health goes on a diet for health, and the $3^{\text {rd }}$ type that pursues additional benefits goes on a diet because of additional benefits which follow the successful diet. This kind of study on the subjectivity of perception of diet can be used as the basic information for the development of diet methods and treatment of obesity. In addition, we anticipate that this can be used also as the basic information for the development of differentiated education programs to be provided to nursing students in their undergraduate years.

However, this study has limitations in the generalization of the results since the research was conducted only at one certain university and could not select respondents in consideration of factors influencing the perception of diet. Therefore, it is necessary to subsequently verify the 3 types by drawing Q-sample from various backgrounds.

\section{References}

[1] Choi, J. H., “Cover story," Retrieved October 1, 2014. From http://seoul.co.kr/news/newsView.php? id $=20131102014001 \&$ spage $=1 \&$ date $=2013-11-02$, (2013)

[2] H. M. Choi, J. H. Kim, J. H. Lee, C. I Kim, K. H. Song, and K. J. Chang, "Essentials of Nutrition," 3rd ed. Paju: Kyomunsa, pp.150-151, (2011)

[3] J. P. Montani, Y. Schutz, and A. G. Dulloo, "Dieting and weight cycling as risk factors for cardiometabolic diseases: who is really at risk?” Obes Rev, vol.16, no.S1, pp.7-18, (2015) DOI:10.1111/obr.12251

[4] S. Dyess and C. Parker, "Transition support for the newly licensed nurse: A program that made a difference," Journal of Nursing Management, vol.20, pp.615-623, (2012) DOI:10.1111/j.1365-2834.2012.01330.x

[5] W. Stephenson, "Q-methodology, interbehavioral psychology and quantum theory," Psychol Record, vol.32, pp.235-248

[6] S. M. Whang, S. W. You, J. Y. Kim, and R. G. Kim, "Consumer Types and Cultural Consumption Characteristics of Korean Society: Who Spends for What Reasons?” Journal of Human Subjectivity, vol.13, pp.25-39, (2006)

[7] S. Jang, "The Subjectivity for Open Adoption of Nursing Students," International Journal of Advanced Nursing Education and Research, vol.3, no.1, pp.59-64, (2018) DOI:10.21742/IJANER.2018.3.1.10

[8] M. Wang, S Kim, and S Jang, "Study of Subjectivity on Death in Korean Elderly," International Journal of Elderly Welfare Promotion and Management, vol.2, no.2, pp.37-42, (2018) DOI:10.21742/IJEWPM.2018.2.2.07 